\title{
Preventivni programi za rano otkrivanje raka dojke u Republici Hrvatskoj Prevention programs for early detection of breast cancer in Croatia
}

\author{
Ivona Šiško, Nikolina Šiško \\ University Hospital Centre Zagreb „Rebro“, 10000 Zagreb, Kišpatićeva 12, Croatia \\ Klinički bolnički centar Zagreb „Rebro“, 10000 Zagreb, Kišpatićeva 12, Hrvatska
}

\begin{abstract}
Sažetak
Nacionalni program za rano otkrivanje raka dojke „Mamma“ uključuje sve žene u Republici Hrvatskoj u starosnoj dobi od 50 do 69 godina. Program sadržava pregled dojki mamografijom svake dvije godine. Ženama na kućnu adresu stiže poziv za besplatan pregled. Cilj je programa smanjiti smrtnost od raka dojke za $25 \%$ do $30 \%$, otkriti rak u početnom stadiju te poboljšati kvalitetu života bolesnica s rakom dojke.

Dobro organiziran i vođen program probira raka mora biti znanstveno utemeljen, dugoročno isplativ, s primjenom metoda dobre prakse. Pozitivnim ispitanicima nakon probira treba biti omogućena adekvatna dijagnostika i liječenje. Nacionalni program ranog otkrivanja raka dojke započeo je krajem 2006. godine. U prvom ciklusu na mamografiju je pozvano ukupno 720.981 žena, a odazvalo se $58,5 \%$. Otkriveno je preko 1500 pozitivnih nalaza. Drugi ciklus programa uključio je 680.552 žena, odaziv je iznosio 57\%, a otkriveno je 928 karcinoma. Treći ciklus započeo je krajem 2011. godine i trajao je do svibnja 2014. godine, a četvrti je započeo u svibnju 2014. godine i završio u jesen 2016 godine.

Od raka dojke najččšce obolijevaju žene iznad pedesete godine života. Muškarci rjeđe obolijevaju. Uzrok nastanka bolesti je nepoznat. Međutim, epidemiološke studije pokazuju postojanje više rizičnih čimbenika koji su povezani s nastankom raka dojke.

Svojim znanjem, vještinama i sposobnostima medicinska sestra/tehničar educira populaciju o zdravlju kako bi podigla samosvijest. Kako bi program probira bio što efikasniji potrebno je omogućiti što veći odaziv u općoj populaciji. Svrha je ovog programa dobrobit cijele zajednice, ali treba poštovati svakog pojedinca, time i njegovu odluku o nesudjelovanju u probiru. Medicinske sestre/tehničari potiču žene na odaziv motiviranjem i edukacijom.
\end{abstract}

Ključne riječi: rak dojke • nacionalni preventivni program • medicinske sestre • samopregled dojki • mamografija • ultrazvuk

Kratki naslov: Preventivni programi i otkrivanje raka dojke

\begin{abstract}
The national program for early detection of breast cancer, "Mamma" includes all female in the Republic of Croatia within the age range from 50 to 69 years. The program includes breast examination with usage of mammography every two years. Participants received the written call for free participation in mammography exam at home addresses. The goal of the program is to reduce the mortality caused of breast cancer from $25 \%$ to $30 \%$, detect cancer at an early stage and improve the quality of life of the patients with breast cancer.

Well organized and led program of screening cancer must be scientifically based; long-term cost must be low, with the application of the basic principles of best evidence-base practice. Positive participants after screening should be provided with adequate diagnosis and treatment. Early detection of breast cancer started with the implementation at the end of 2006. In the first cycle of the program included were total of 720,981 female, and the response was $58.5 \%$. More than 1,500 positive findings were discovered. In the second cycle it was included 680,552 female, turnout was $57 \%$, and it was revealed 928 positive findings of breast cancer. The third cycle began in late 2011 and lasted until May 2014. The fourth cycle of the program started in May 2014 and finished at autumn 2016.

Breast cancer primarily affects women over fifty years old. Men rarely suffer from this illness. The cause of the disease is unknown. However, epidemiological studies verified the existence of multiple risk factors associated with the development of breast cancer.

With their knowledge, skills and abilities nurses educate the population about their health status in order to raise the level of self-awareness.Screening program must be efficient, and at the same time it is necessary to provide the response from most of the targeted population. The purpose of this program is to increase the awareness for early prevention among participants and in the whole community, but at the same time it should respect each individual, respect their decision to participate or not in the screening. Nurses encourage female population for participating in such programs.
\end{abstract}

Keywords: breast cancer $•$ national prevention program • nurse • self-examination of the breast • mammography $•$ ultrasound

Running head: Prevention programs and detection of breast cancer 


\section{Uvod / Introduction}

Kada se na određenom zemljopisnom području provode individualni ili populacijski preventivni zdravstveni pregledi u svrhu ranog otkrivanja maligne bolesti to govori o visokom stupnju zdravstvene prosvjećenosti stanovništva koje svojim odazivom na preglede pokazuje da brigu o osobnom zdravlju smatra obvezom prema sebi i društvu [1].

Zahvaljujući naporima Hrvatskog onkološkog društva Hrvatskog liječničkog zbora, Republika Hrvatska [RH] država je u kojoj su kvalitetno pripremljeni i pokrenuti Nacionalni programi prevencije malignih bolesti. Dobro planirani, dugogodišnje provedivi i stručno praćeni programi smanjuju pojavnost i smrtnost nastanka malignih bolesti do jedne trećine. Probir ili dijagnosticiranje u zdravoj populaciji, s ciljem da se maligna bolest dijagnosticira prije kliničkih manifestacija najbolja je metoda ranog otkrivanja.

Zdravstveni je tim koji se susreće sa ženama u probiru ranog otkrivanja raka dojke multidisciplinaran. Uloga je medicinske sestre/tehničara da svojim znanjem, vještinama i sposobnošću ženskoj populaciji pomogne da usvoje isto. Taj tim aktivno sudjeluje u kreiranju i provođenju postupaka očuvanja zdravlja i pomaže ženama da prihvate odgovornost za svoje zdravlje. Promicanjem važnosti redovitog samopregleda i mamografije, medicinska sestra/tehničar povećava stupanj svijesti o važnosti ranog otkrivanja raka dojke te aktivno sudjeluje u provođenju preventivnih programa.

\section{[1] Dijagnostika raka dojke}

Prema American Cancer Society preporuke za detekciju raka dojke jesu:

Ad 1] za žene u starosnoj dobi od 20 do 40 godina preporuča se redoviti mjesečni samopregled [8-10 dana nakon prvog menstrualnog krvarenja]; klinički pregled jedanput u dvije godine, te pregled ultrazvukom i mamografija fakultativno;

Ad 2] za žene u starosnoj dobi od 40 do 50 godina preporuča se redoviti samopregled jedanput mjesečno, klinički pregled jedanput godišnje, mamografija svake dvije godine, ultrazvuk fakultativno;

Ad 3] za žene iznad 50 godina starosti uz redoviti samopregled, preporuča se klinički pregled jedanput godišnje, mamografija svake godine i ultrazvuk fakultativno [2].

\section{[1.1.] Samopregled dojki}

Samopregled dojke značajan je jer ga žena može obaviti sama bez teškoća i bilo kakvih posljedica. Istim se ne može verificirati postojanje početnog stadija raka dojke, ali uporabom istoga u značajnom obimu se smanjuje incidencija razvoja.

Svrha samopregleda otkrivanje je tumora dojke dok je ograničen samo u dojci. Žene koje redovito obavljaju samopregled žive duže otkrije li se rak i pravovremeno se počne odgovarajuće liječenje.

Stupanj godišnjeg preživljenja poslije provedenog kirurškog zahvata liječenja karcinoma dojke na godišnjoj razini iznosi 79\%, dok u žena koje ne provode samopregled preživljenje iznosi $61 \%$.

\section{[1.2.] Klinički pregled}

Klinički pregled uključuje anamnezu, inspekciju i palpaciju. Anamneza se sastoji od obiteljske i osobne anamneze. Obiteljska anamneza detaljno informira liječnika o svim bolestima ili uzrocima smrti u članova obitelji s posebnim naglaskom na ženke osobe.

Osobna anamneza daje podatke iz života i dotadašnjih bolesti pacijentice. Također se informira o prethodnim liječničkim pregledima dojke i vremenu koji je prošao od posljednja pregleda. Inspekcijom se dobivaju podatci o etiologiji i faktorima rizika bolesti. Palpacijom se određuje veličina, oblik, površina, konzistencija, pomičnost, ograničenost prema okolini, bolnost i sijelo tumora u dojci. Pregled se nadopunjuje pregledom pazušnih udubina.

\section{[1.3.] Pregled uporabom ultrazvuka}

Pravilnom upotrebom dijagnostičkih sredstava, dobroćudne i zloćudne novotvorine verificiraju se točnošću od $98 \%$. Ultrazvučna dijagnostika dojke najpristupačnija je, najjeftinija i bezopasna metoda pregleda, ali ograničenih mogućnosti kod otkrivanja nekih vrsta ranog stadija raka dojke. $U$ dijagnosticiranju dobroćudnih i upalnih promjena dojke, ultrazvučni pregled je na prvom mjestu i kod značajnog broja bolesnica predstavlja dostatnu metodu pretrage te nije potrebno činiti dodatne dijagnostičko-terapeutske postupke. Za žene mlađe od 35 godina, trudnice i dojilje ultrazvučni pregled predstavlja tzv. „zlatni standard”, a dodatne metode pretrage su mamografija i galaktografija.

\section{[1.4.] Mamografija}

Mamografija je radiološka metoda snimanja dojki bez primjene kontrastnog sredstva. Najučinkovitija i najznačajnija je metoda dijagnosticiranja patoloških stanja dojke. U dijagnostici klinički okultnog karcinoma dojke predstavlja "zlatni standard". Oko 10\% palpabilnih oblika tumora nije uočljivo na mamografiji. Negativan nalaz nije dovoljan za isključenje maligniteta u klinički simptomatske pacijentice. Kombinacijom ultrazvučnog pregleda i mamografije postiže se točnost u verifikaciji dijagnoze od $98 \%$, uz napomenu da su podatci dobiveni tijekom kliničkog pregleda zadovoljavajući.

\section{[2] Nacionalni program ranog otkrivanja raka dojke}

Nacionalni programi prevencije raka javnozdravstveni su programi kojima je cilj smanjenje broja oboljelih i umrlih od raka te poboljšanje stupnja kvalitete života osobama s verificiranom malignom bolesti. Maligna bolest uzrokuje značajne financijske i psihosocijalne poteškoće za bolesnike i članove obitelji, kao i za društvo u cjelini. Cilj je nacionalnog programa za kontrolu raka smanjiti broj oboljelih i umrlih od te bolesti, smanjiti nejednakost i poboljšati kvalitetu života oboljelih kao i članova njihovih obitelji bez štetnih posljedica za zdravlje sudionika u programu. 
Dobro organiziran i vođen program probira u općoj populaciji uvelike je uspješniji nego u slučajevima tzv. oportunističkog pristupa, tj. kada se pregled izvodi isključivo na zahtjev pojedinca. "Takav program mora biti znanstveno utemeljen, dugoročno isplativ, izgrađen na primjerima dobre prakse, a dobrobiti i ograničenja svakog probira moraju biti prikazana pučanstvu kako bi ono samo moglo odlučiti o svojem sudjelovanju u programu" [4].

U RH godišnje oboli oko $24 \%$ žena. U 2002. godini u svijetu je karcinom dojke dijagnosticiran u 1150000 slučajeva, a smrtni ishod zabilježen je u 414000 žena. U RH je 2004. godine zabilježeno 2131 novooboljelih. Incidencija raka dojke u stalnom je porastu, a pad mortaliteta uočio se nakon provedbe preventivnog programa. Provođenjem mamografije dokazan je smanjeni mortalitet koji iznosi od 20 do $35 \%$ u žena starosne dobi od 50 do 69 godina. Ukoliko se karcinom otkrije rano, petogodišnje preživljavanje iznosi do $97 \%$. Pristup probiru je kompleksan. Isti moraju provoditi educirani zdravstveni djelatnici , a potrebno je uporabiti moderne tehnologije. U programe prevencije potrebno je uvrstiti zdrave žene bez simptoma koje treba informirati na prikladan način o dobrim i lošim stranama probira kako bi same odlučile o sudjelovanju u programu. Najveća dobrobit rano je otkrivanje raka dojke i posljedično smanjenje stupnja smrtnosti. Neželjeni su učinci povećanje stupnja straha i komorbiditeta, neodgovarajući ekonomski troškovi i prekomjerna uporaba ionizirajućeg zračenja.

\section{[3] Program ranog otkrivanja raka dojke u Republici Hrvatskoj}

Nacionalni program ranog otkrivanja raka dojke u RH usvojen je na sjednici Vlade RH 29. lipnja 2006. godine, a u skladu je s odrednicama Nacionale strategije prevencije i ranog otkrivanja raka te s Rezolucijom o prevenciji i kontroli karcinoma [5].

Nosilac Nacionalnog programa ranog otkrivanja raka dojke "Mamma" Ministarstvo je zdravstva i socijalne skrbi RH, a za provođenje imenovani su koordinatori u županijskim zavodima za javno zdravstvo. Cilj je programa smanjenje mortaliteta od raka dojke za $25 \%$ u pet godina nakon početka programa te verifikacija u većem postotku karcinoma dojke u lokaliziranom (ranom) stadiju, što utječe na povećanje stupnja kvalitete života bolesnica i značajno smanjuje ekonomske troškove liječenja uznapredovanoga stadija bolesti. Ciljna populacija za uključenje u navedeni program žene su starosne dobi od 50 do 69 godina. Metoda probira je mamografija, i to svake druge godine s uključenjem prema općoj populaciji u obimu od najmanje $70 \%$. Nacionalni program započeo je 2. listopada 2006. godine.

Metodologija provođenje programa: Pozivi se šalju u omotnicama s unaprijed tiskanim adresama koje područnom/regionalnom zavodu za javno zdravstvo šalje Ministarstvo zdravstva i socijalne skrbi $\mathrm{RH}$. Na pozivu je naveden datum, sat i mjesto gdje se žena treba javiti na pregled. Taj termin dogovara zavod s mamografskim jedinicama na svom području koje su potpisale ugovor s HZZO-om o sudjelovanju. Uz poziv ženama se daje anketni list koji treba ispuniti, kupovnicu koja se predaje prilikom pregleda, te edukativnu knjižicu o dojci. Anketni list sadrži pitanja o dobi žene, prvoj menstruaciji, broju poroda, s koliko je godina žena prvi put rodila, povijesti i trajanju dojenja, korištenju oralnih kontraceptiva, korištenju zamjenske hormonske terapije, menopauzi, s koliko je godina nastupila menopauza, obiteljskoj anamnezi o karcinomu dojke, simptomima bolesti, poduzetim mjerama uz postojeću bolest, težini, visini, datumu zadnje napravljene mamografije [5].Dobija se i omotnica za radiologa u koju se stavlja nalaz i slika za liječnika primarne zdravstvene zaštite. Ukoliko žena traži odgovor na specifično pitanje, želi li odgoditi pregled,ili je u tekućoj godine već obavila mamografski pregled, ili se pak liječi od neke bolesti dojke, javlja se na besplatni telefon zavoda. Nalaz mamografije stiže nakon tri tjedna, a da bi se osigurala kvaliteta nalaza upotrebljava se dvostruko neovisno [slijepo] čitanje snimaka. Ukoliko je nalaz zadovoljavajući, ženi se odašilje poziv za rutinski pregled i to dvije godine poslije učinjenog prvotnog pregleda. Ako je nalaz abnormalan, ženi i obiteljskom liječniku šalju se informacije o daljnjim potrebnim koracima za procjenu stanja. Na pozivu žena potpisuje da je upoznata da se mamografijom ne mogu uvijek prepoznati karcinomi dojke (15-20\%), posebice radi li se o dojkama s gustom žljezdanom strukturom. Stoga je potrebno da se kod guste strukture dojke učini komplementarni ultrazvučni pregled radi otkrivanja patoloških promjena koje se ne mogu zabilježiti mamografskim pregledom. Superviziju i evaluaciju programa izvršavaju članovi zdravstvenih timova područnih zavoda za javno zdravstvo.

\section{[3.1.] Rezultati provedenog istraživanja}

Prvi ciklus programa proveden je u razdoblju od kraja 2006. do kraja 2009. godine. U istraživanje su uključene žene $s$ godinama rođenja od 1937. do 1958. godine. U prvom ciklusu pozvane su ukupno 720982 žene, a mamografiju je izvršilo 331.609 žena. Odaziv se razlikuje po županijama, a za $\mathrm{RH}$ ukupno iznosi 63\%. Broj suspektnih nalaza bio je 3431 [1,03\%], a verificiranih malignih bolesti dojke 1593 [0,50\%]. Drugi ciklus programa odvijao se od početka 2010. do kraja 2011. godine. Uključene su bile žene s godinama rođenja od 1940. do 1960. Pozvane su 680552 žene, a mamografski pregled je učinjen u 295.605 žena. Odaziv je iznosio 57\%. Otkriveno je 928 karcinoma. Treći ciklus počeo je krajem 2011. godine i trajao je do svibnja 2014. Četvrti je počeo u svibnju 2014., a završen je u jesen 2016. godine.

\section{[4] Uloga medicinske sestre/tehničara u ranom otkrivanju raka dojke}

Uloga medicinske sestre/tehničara u ranom otkrivanju raka dojke i njegovoj prevenciji od izuzetne je važnosti. Aktivna se uloga može podijeliti na tri cjeline, i to: - medicinska sestra/tehničar kao odgajateljica, učiteljica te kao praktičar. Kao odgajateljica i učiteljica pomaže ženskoj populaciji da usvoji potrebna znanje i da ista aktivno provode. Usvojenim znanjem potrebno je mijenjati nezdravo ponašanje u zdravo. Medicinska sestra/tehničar praktičar koristi znanje, vještine i sposobnosti za prepoznavanje i utvrđivanje aktivnog problema te planira i provodi metode zdravstvene njege. U svoj rad po potrebi uključuju stručnja- 
ke različitih znanstveno-stručnih grana kako bi zadovoljila sve možebitne probleme. Potiče i pomaže ženskoj populaciji da aktivno s njom sudjeluje u kreiranju i provođenju postupaka koji će unaprijediti stupanj zdravlja. Najvažniji dio u kojem sudjeluje pomaganje ženskoj je populaciji da prihvati odgovornost za osobno zdravlje. Prihvaćanjem odgovornosti za osobno zdravlje, uklanjanjem nelagode, stida i straha, ženska populacija u povećanom obimu provodi odgovarajuće samopreglede, redovite liječničke preglede i mamografiju [6].

\section{Zaključak / Conclusion}

Početni rezultat Programa za rano otkrivanje raka dojke u RH pokazao je zadovoljavajuće rezultate. Uvedena su značajna poboljšanja prema iskustvima iz prijašnjih programa probira u svrhe prevencije maligne bolesti dojke. Osim poboljšanja stupnja morbiditeta i mortaliteta, poboljšava se uspješnost dijagnosticiranja i liječenje karcinoma, te se značajno smanjuje rizik u detekciji nastanka te u kvaliteti zaštite od bolesti dojke između županija RH. Zdravstveni tim koji sudjeluje u probiru kontinuirano se educira. Općeprisutni su problemi kod provođenja Programa nedovoljna medijska zastupljenost i financijska podrška, nedostatni kadrovi u sprovođenju dijelova programa, niska zdravstvena prosvijećenost populacije u pojedinim područjima, netočne adrese te udaljenost od dijagnostičkih jedinica [4].

Kontinuiran rad medicinskih sestara/tehničara na svim razinama zdravstvene zaštite, posebno u primarnoj zdravstvenoj zaštiti, od velike je važnosti za pravovremeno ot- krivanje karcinoma dojke. Značajan broj oboljelih, novi postupci i metode liječenja, produljenje tijeka života oboljelih uzrokuje potrebu provođenja trajnih metoda edukacije u sestrinskoj zajednici u RH. Intervencije medicinske sestre/ tehničara usmjerene su na provođenje metoda prevenciju raka dojke, rano otkrivanje, rješavanje problematike u sestrinskoj zajednici pri dijagnostičkim postupcima, liječenju i tijekom oporavka. Medicinska sestra/tehničar danas mora posjedovati visoki stupanj znanja i vještine za provođenje edukacije opće populacije. Neprekidnim ukazivanjem na važnost kontroliranja osobnog zdravlja, redovitim odlaskom na liječničke preglede i mamografiju te povećanjem pozitivnog stava pojedinaca prema samopregledu postiže se značajno poboljšanje u stupnju rane detekcije malignih bolesti dojke.

\section{Authors declare no conflict of interest}

\section{Literatura / References}

[1] Margaritoni M. Rak dojke. Zagreb: Školska knjiga; 1993.

[2] Štula N. Sekundarna prevencija raka dojke "rana detekcija“: bilten. 2000.

[3] Janković S. Mamografija i ultrazvuk dojke (poslijediplomski tečaj 1. kategorije - tečaj stalnog medicinskog usavršavanja liječnika). Split: Jedinica za znanstveni rad Kliničke bolnice Split; 2004.

[4] Strnad M, Šogorić S. Rano otkrivanje raka u Hrvatskoj. Acta Med Croatica. 2010; 64:461-468.

[5] Pavlović I. What kind of education about breast cancer women need. Libri oncologici. 2002; 13-16.

[6] Vujanić E. Uloga medicinske sestre kod ranog otkrivanja raka. Shock. 2014; 96-90. 